\title{
Pengaruh Multimedia Interaktif dalam Pembelajaran Matematika Terhadap Kemampuan Komunikasi Matematis Siswa
}

\author{
Ibnu Sina ${ }^{1}$, Ehda Farlina ${ }^{2}$, Sukanto Sukandar ${ }^{3}$, Rahayu Kariadinata $^{4}$ \\ 1,2,4 Mathematics Education Departement, UIN Sunan Gunung Djati Bandung \\ ${ }^{3}$ Mathematics Education, STKIP Garut \\ e-mail: ehda.farlina@uinsgd.ac.id
}

\begin{abstract}
ABSTRAK. Penelitian ini bermaksud untuk mengetahui kemampuan komunikasi matematis siswa yang memperoleh pembelajaran dengan menggunakan media pembelajaran Adobe Flash. Sampel dalam penelitian ini sebanyak 33 siswa dengan menggunakan desain Classroom Action Research pada pokok bahasan segiempat. Instrumen yang digunakan diantaranya lembar observasi, skala sikap, tes setiap siklus, dan tes akhir. Berdasarkan hasil penelitian diperoleh kemampuan komunikasi matematis siswa yang memperoleh pembelajaran dengan menggunakan media Adobe Flash diseluruh siklus mengalami peningkatan dengan kriteria baik dengan jumlah siswa yang memenuhi kriteria sebanyak 20 siswa dari 32 siswa dan persepsi siswa terhadap penggunaan Adobe Flash dalam pembelajaran Matematika pada umumnya positif. Hal ini merangsang siswa untuk mengembangkan ide-ide dan membangun pengetahuan pada kesempatan lainnya.
\end{abstract}

Keywords : Adode Flash, Komunikasi, Siklus.

\section{PENDAHULUAN}

Kemampuan komunikasi adalah kemampuan menyampaikan informasi baik secara tulisan ataupun lisan kepada orang lain. Kemampuan komunikasi matematis merupakan salah satu kemampuan yang harus dimiliki oleh siswa. Hal ini dikarenakan kemampuan komunikasi matematis dapat menjelaskan pemahaman matematis siswa secara mendalam (Paridjo; Waluya, 2017). Ada dua alasan penting mengapa komunikasi dalam matematika perlu ditumbuhkembangkan pada siswa. Pertama, mathematics as language, sebagai alat yang berharga untuk mengkomunikasikan berbagai ide secara jelas, tepat dan cermat. Kedua, mathematics learning as social activity; sebagai aktivitas sosial dalam pembelajaran matematika, baik interaksi antar siswa atau interaksi antara guru dengan siswa (Baroody, 1993).

Proses komunikasi yang baik berpotensi merangsang siswa untuk mengembangkan ide-ide dan membangun pengetahuan matematisnya (Nurismayanti, 2014). Namun, kenyataan di lapangan bahwa kemampuan komunikasi matematis siswa jarang mendapat perhatian. Guru lebih menekankan agar siswa mampu menjawab soal dengan benar tanpa meminta alasan dari siswa, ataupun meminta siswa untuk mengkomunikasikan pemikiran, ide serta gagasannya (Aesih, 2014). Kemampuan komunikasi matematis juga masih rendah (Kirana, 2014) dan belum optimal (Utami, Dwijayanto, \& Djuniadi, 2015). Sehingga diperlukan upaya untuk meningkatkan kemampuan komunikasi matematis siswa.

Salah satu cara yang dapat dilakukan untuk menjadikan pembelajaran matematika diharapkan dapat meningkatkan hasil belajar dan lebih kondusip adalah dengan menggunakan media pembelajaran multimedia dalam proses pembelajaran matematika (Minarti, 2014). Multimedia yang digunakan dapat berupa multimedia interaktif dengan memanfaatkan kemajuan teknologi yang berkembang sekarang. Multimedia interaktif merupakan gabungan gambar, video, 
animasi, dan suara dalam satu perangkat lunak (software) yang memungkinkan pengguna untuk berinteraksi secara langsung (Novitasari, 2016). Salah satu multimedia interaktif yang digunakan Adobe Flash. Adobe Flash mudah dipelajari tanpa harus memiliki pengetahuan tentang bahasa pemrograman (Aji, Hudha, \& Gufran, 2018). Adobe flash adalah aplikasi yang dipakai luas oleh para profesional web karena kemampuannya yang mengagumkan dalam menampilkan multimedia, menggabungkan unsur teks, grafis, animasi, suara dan serta interaktivitas bagi pengguna (Supriyadi, 2016).

Berdasarkan permasalahan tersebut, maka perlu dilakukan sebuah inovasi dalam pembelajaran Matematika agar kemampuan siswa dapat dioptimalisasikan terutama kemampuan komunikasi matematis siswa. Sehingga dalam penelitian ini akan dilihat bagaimana peningkatan kemampuan komunikasi matematis siwa pada setiap siklusnya.

\section{METODE}

Metode yang digunakan adalah Classroom Action Research. Empat tahapan dalam Classroom Action Research yaitu perencanaan, tindakan, pengamatan, dan refleksi. Subjek pada penelitian ini adalah siswa kelas VII SMP dengan sampel yang sebanyak 35 siswa, sesuai dengan rekomendasi guru matematika. Instrumen yang digunakan berupa lembar observasi dan skala sikap, tes setiap akhir siklus dan tes akhir setelah seluruh siklus telah terlaksanakan.

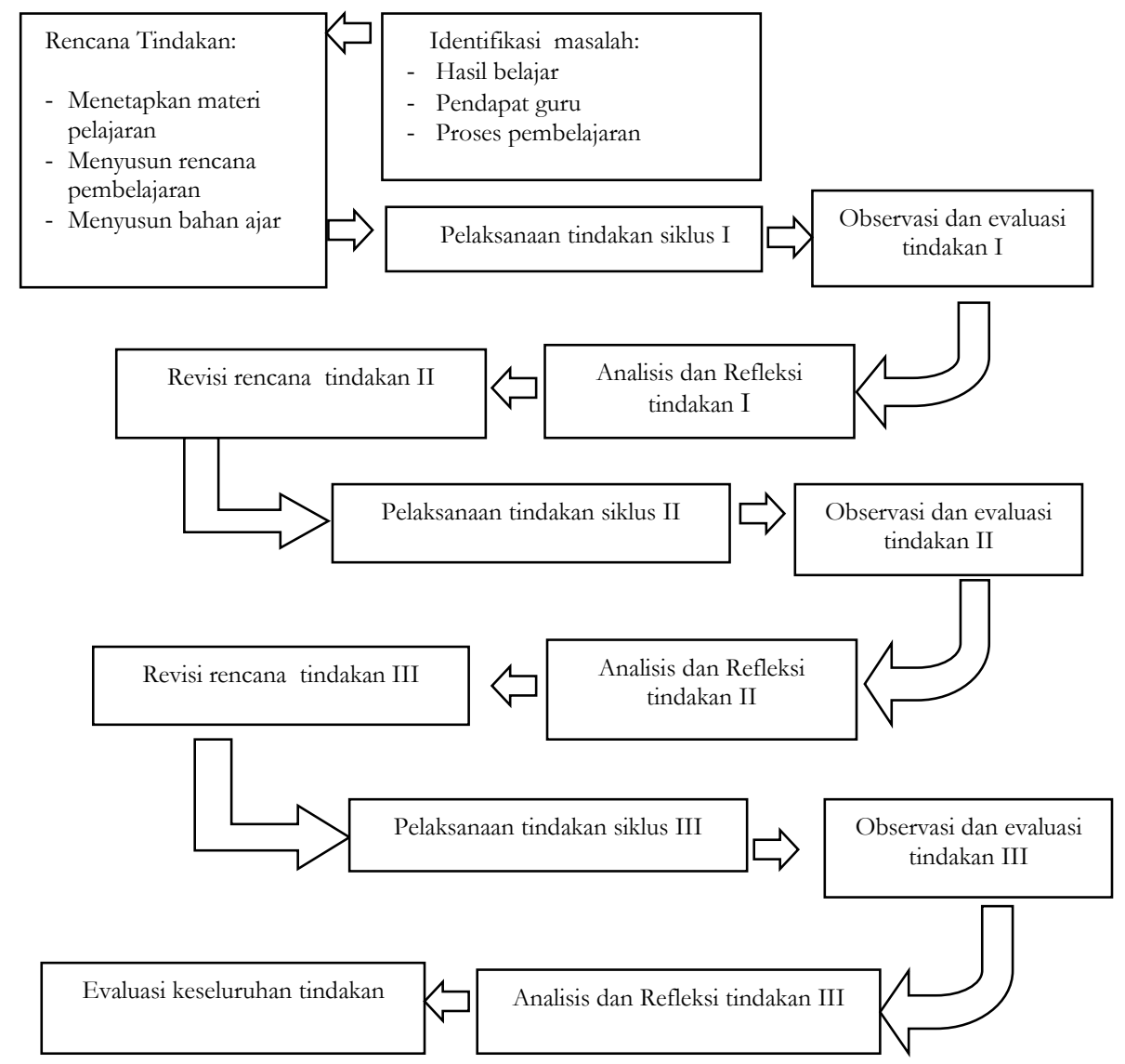

Gambar 1. Siklus Pembelajaran dengan Media Adobe Flash 


\section{HASIL DAN PEMBAHASAN}

\section{Pembuatan Media Pembelajaran Adobe Flash}

Ada beberapa versi dari software Adobe Flash diantaranya Adobe Flash CS3, Adobe Flash CS5 dan Adobe Flash CS6. Versi yang digunakan dalam penelitian ini adalah Adobe Flash CS. Menurut Luther (Sutopo, 2003), metodologi pengembangan multimedia terdiri dari enam tahap, yaitu: Concept, Design, Material collecting, Assembly, Testing, Distribution.

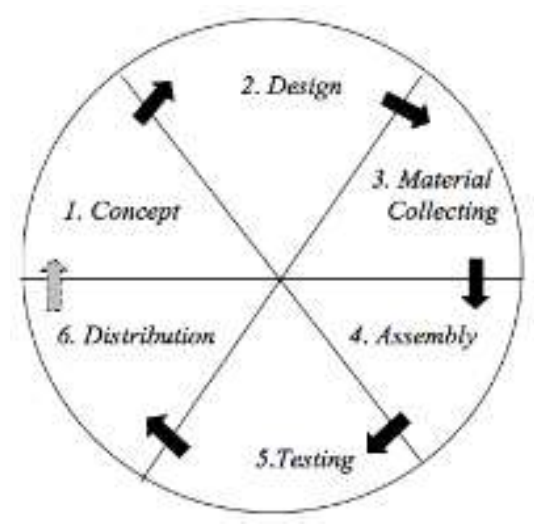

Gambar 2. Alur Pengembangan Media

a. Concept (Tahap Pengkonsepan)

Tahap concept (pengkonsepan) adalah tahap untuk menetukan tujuan dan siapa pengguna program (identifikasi audiens). Tujuan dari pembuatan media pembelajaran dengan menggunakan Adobe Flash ini yaitu untuk meningkatkan kemampuan komunikasi matematika siswa pada pokok bahasan segitiga dan segiempat.

\section{b. Design (Tahap Perancangan)}

Design (perancangan) adalah tahap pembuatan spesifikasi mengenai arsitektur program, gaya, tampilan, dan kebutuhan material/bahan untuk program. Adapun rancangan media pembelajaran yang akan dibuat menggunakan Adobe Flash dapat dilihat pada Gambar 3.

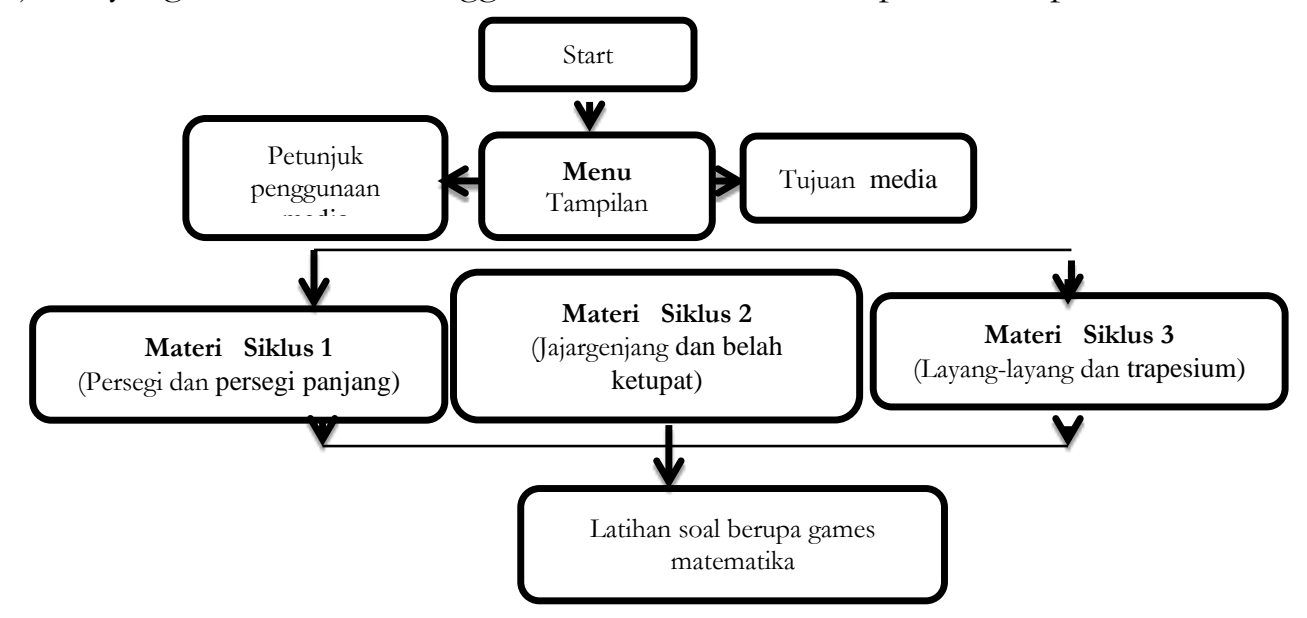

Gambar 3. Tahapan Design

c. Material Collecting (Tahap Pengumpulan Bahan)

Material Collecting adalah tahap pengumpulan bahan yang sesuai dengan kebutuhan yang dikerjakan.Bahan-bahan tersebut, antara lain gambar clip art, foto, animasi, video, audio, dan lainlain. maka, dari itu peneliti memerlukan pengumpulan bahan bahan yang diperlukan untuk pembuatan media ini yaitu : 


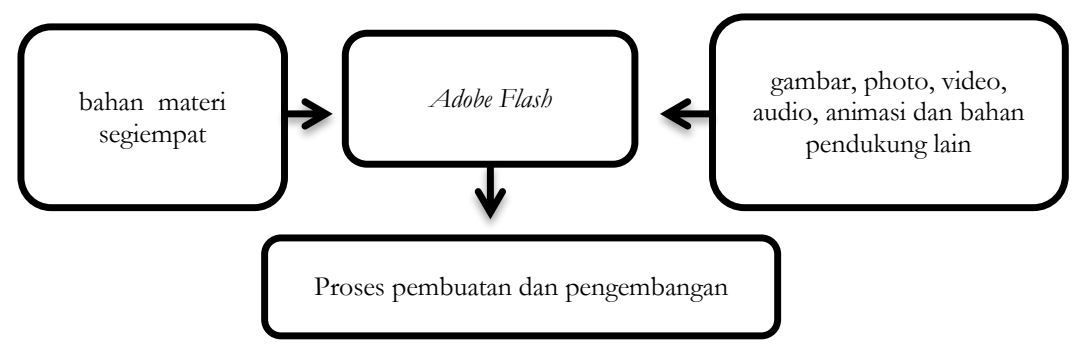

Gambar 4. Tahapan Pengumpulan Bahan

d. Assembly (Tahap Pengembangan)

Tahap assembly adalah tahap pembuatan semua obyek atau bahan multimedia. Pembuatan aplikasi didasarkan pada tahap design, seperti storyboard, bagan alir, dan/atau struktur navigasi. Berikut tampilan awal media yang telah dikembangkan dari rancangan awal.

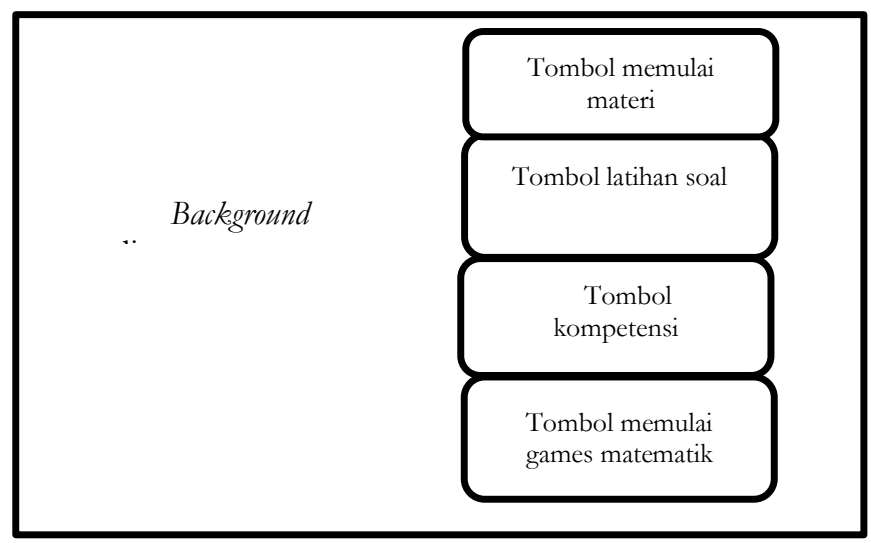

Gambar 5. Tahap Pengembangan

Kemudian desain awal tersebut akan dikembangkan lagi agar terlihat lebih menarik dengan menambahkan bahan-bahan yang telah dikumpulkan. Berikut hasil pengembangan dari desain awal media dapat dilihat pada Gambar 6.

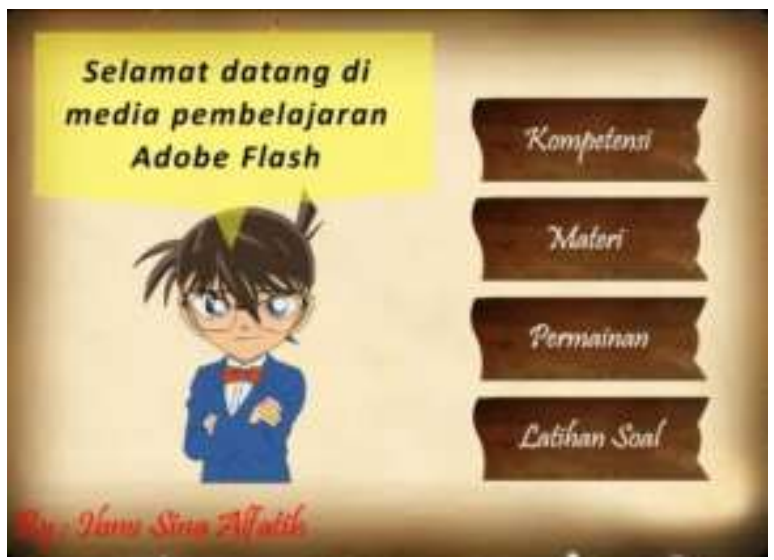

Gambar 6. Pengembangan Tampilan Awal

\section{e. Testing (Tahap Uji Coba)}

Tahap Testing (pengujian) dilakukan setelah menyelesaikan tahap pembuatan (assembly) dengan menjalankan aplikasi/program dan melihatnya apakah ada kesalahan atau tidak. Tahap pertama 
pada tahap ini disebut tahap pengujian alpha (alpha test) yang pengujiannya dilakukan oleh pembuat atau lingkungan pembuatnya sendiri. Setelah lolos dari pengujian alpha, pengujian beta yang melibatkan pengguna akhir akan dilakukan. Berdasarkan hasil analilsis validasi uji coba media, diperoleh hasil bahwa media pembelajaran Adobe Flash layak digunakan sebagai salah satu media pembelajaran yang berfungsi untuk membantu dan memudahkan menyampaikan meteri pelajaran matematika kepada siswa agar siswa menjadi lebih termotivasi untuk belajar matematika.

\section{f. Distribution}

Pada tahap ini, aplikasi akan disimpan dalam suatu media penyimpanan. Jika media penyimpanan tidak cukup untuk menampung aplikasinya, kompresi terhadap aplikasi tersebut akan dilakukan. Tahap ini juga dapat disebut tahap evaluasi untuk pengembangan produk yang sudah jadi supaya menjadi lebih baik. Hasil evaluasi ini dapat digunakan sebagai masukan untuk tahap concept pada produk selanjutnya.

\section{Hasil Setiap Siklus}

\section{Siklus I (Pertama)}

Gambaran aktivitas siswa dalam proses pembelajaran Matematika dengan menggunakan Adobe Flash pada pertemuan pertama atau siklus pertama terdapat pada Tabel 1. Berdasarkan hasil observer, aktivitas siswa pada siklus I masih tidak kondusif dan terdapat beberapa siswa yang mencontek serta berdiskusi ketika tes berlangsung.

Tabel 1. Gambaran Aktivitas Siswa pada Siklus I

\begin{tabular}{ccll}
\hline $\begin{array}{c}\text { Tahap } \\
\text { Pembelajaran }\end{array}$ & Keterlaksanaan & Interpretasi & \multicolumn{1}{c}{ Komentar Observer } \\
\hline Tahap I & $75 \%$ & Cukup & $\begin{array}{l}\text { Beberapa siswa tidak } \\
\text { memperhatikan guru. }\end{array}$ \\
Tahap II & $83 \%$ & Baik & $\begin{array}{l}\text { Beberapa siswa masih ribut dan tidak } \\
\text { memperhatikan guru }\end{array}$ \\
Tahap III & $75 \%$ & Cukup & $\begin{array}{l}\text { Ada beberapa siswa yang } \\
\text { mencontek dan berdiskusi ketika } \\
\text { tes berlangsung }\end{array}$ \\
\hline
\end{tabular}

\section{Keterangan :}

Tahap I : tahap pendahuluan

Tahap II : tahapan pembelajaran dengan media pembelajaran Adobe Flash

Tahap III : tahap penutup

Sedangkan rata-rata aktivitas guru selama pembelajaran siklus I mencapai $92 \%$ dengan kriteria sangat baik. Adapun tanggapan dari observer mengenai aktivitas guru selama siklus I berlangsung adalah: di awal pembelajaran guru kurang memotivasi dan memberikan apersepsi kepada siswa,sehingga guru belum maksimal dalam melaksanakan pembelajaran, guru kurang tegas dalam menyikapi siswa yang ribut, sehingga banyak siswa yang belum menanggapi proses pembelajaran yang dilaksanakan, dan guru kurang pandai dalam mengelola waktu pembelajaran, sehingga terjadi sedikit ketidaktepatan waktu dalam proses pembelajaran.

Siklus I diakhiri dengan refleksi, yang hasilnya dapat dilihat pada Tabel 2. Hasil refleksi menunjukkan bahwa guru masih mengalami kesulitan dalam mengkondisikan siswa saat pembelajaran. 
Tabel 2. Refleksi Siklus I

\begin{tabular}{|c|c|c|}
\hline $\mathrm{NO}$ & Masalah & Pemecahan Masalah \\
\hline 1 & $\begin{array}{l}\text { Guru sulit mengkondisikan kelas } \\
\text { ketika siswa memasuki labolatorium } \\
\text { komputer karena banyak siswa yang } \\
\text { berebutan memilih komputer. }\end{array}$ & $\begin{array}{l}\text { Guru harus lebih tegas dan berlaku adil } \\
\text { kepada seluruh siswa agar siswa tertib dan } \\
\text { tidak saling iri dengan siswa lain ketika } \\
\text { berebutan menggunakan komputer }\end{array}$ \\
\hline 2 & $\begin{array}{l}\text { Pada saat akan memulai pembelajaran } \\
\text { di labolatorium komputer terdapat } \\
\text { beberapa komputer yang tidak bisa } \\
\text { digunakan }\end{array}$ & $\begin{array}{l}\text { Jauh sebelum dilaksanakannya } \\
\text { pembelajaran guru harus mengecek kinerja } \\
\text { komputer yang tersedia. Jika ada beberapa } \\
\text { komputer yang rusak maka guru harus } \\
\text { dapat mengkondisikan kelas agar semua } \\
\text { siswa dapat menjalankan komputer secara } \\
\text { bergantian dan teratur. }\end{array}$ \\
\hline 3 & $\begin{array}{l}\text { Pada saat pembelajaran berlangsung } \\
\text { ada beberapa siswa yang menjalankan } \\
\text { komputer tidak sesuai dengan arahan } \\
\text { guru }\end{array}$ & $\begin{array}{l}\text { Guru harus dapat memantau seluruh siswa } \\
\text { agar tidak ada siswa yang main-main ketika } \\
\text { belajar }\end{array}$ \\
\hline
\end{tabular}

Pada siklus I rata-rata ketuntasan belajar siswa mencapai 74,07\% sebanyak 20 orang. Berarti masih ada 7 siswa yang tidak tuntas dari 27 siswa. Sedangkan kemampuan komunikasi matematis siswa pada tes siklus I dapat dilihat pada Tabel 3. Hasil tes kemampuan komunikasi matematis pada siklkus I memperlihatkan masih ada siswa yang mendapatkan nilai kurang dari batas ketuntasan sebanyak 5 siswa.

Tabel 3. Kemampuan komunikasi matematika siswa pada tes siklus I

\begin{tabular}{ccc}
\hline $\begin{array}{c}\text { Persentase Kemampuan Komunikasi } \\
\text { Matematika }\end{array}$ & Kriteria & Jumlah Siswa \\
\hline $\mathbf{9 0} \leq \mathbf{A} \leq \mathbf{1 0 0}$ & Sangat Baik & 0 \\
$\mathbf{7 5} \leq \mathbf{B}<\mathbf{9 0}$ & Baik & 12 \\
$\mathbf{5 5} \leq \mathbf{C}<\mathbf{7 5}$ & Cukup & 10 \\
$\mathbf{4 0} \leq \mathbf{D}<\mathbf{5 5}$ & Kurang & 5 \\
$\mathbf{0} \leq \mathbf{E}<\mathbf{4 0}$ & Jelek & 0 \\
\hline Total & & 27 \\
\hline
\end{tabular}

\section{Siklus Kedua}

Gambaran aktivitas siswa dalam proses pembelajaran Matematika dengan menggunakan Adobe Flash pada siklus kedua dapat dilihat pada Tabel 4. Pada tahap III, baru terlaksana 75\% karena masih ada siswa yang berdiskusi ketika tes berlangsung.

Tabel 4. Gambaran Aktivitas Siswa pada Siklus II

\begin{tabular}{|c|c|c|c|}
\hline $\begin{array}{c}\text { Tahap } \\
\text { Pembelajaran }\end{array}$ & Keterlaksanaan & Interpretasi & Komentar Observer \\
\hline Tahap I & $100 \%$ & Sangat baik & $\begin{array}{l}\text { Masih ada } \\
\text { yang tidak memperapa siswa } \\
\text { guru }\end{array}$ \\
\hline Tahap II & $100 \%$ & Sangat baik & $\begin{array}{l}\text { Masih ada beberapa siswa yan̨̧ } \\
\text { ribut dan tidak memperhatikar } \\
\text { guru }\end{array}$ \\
\hline Tahap III & $75 \%$ & Cukup & $\begin{array}{lrr}\text { Masih ada } & \text { siswa } & \text { yang } \\
\text { berdiskusi } & \text { ketika } & \text { tes } \\
\text { berlangsing } & & \\
\end{array}$ \\
\hline
\end{tabular}


Rata-rata aktivitas guru selama pembelajaran siklus II mencapai $92 \%$ dengan kriteria sangat baik. Adapun tanggapan dari observer mengenai aktivitas guru selama siklus II berlangsung adalah : di awal pembelajaran guru sudah cukup baik dalam memotivasi dan memberikan apersepsi kepada siswa, sehingga guru sudah maksimal dalam melaksanakan pembelajaran, guru mulai tegas dalam menyikapi siswa yang ribut, karena guru mulai terbiasa dengan sikap siswa, sehingga banyak siswa sudah menanggapi proses pembelajaran yang dilaksanakan, dan guru sudah pandai dalam mengelola waktu pembelajaran, sehingga tidak lagi terjadi sedikit ketidaktepatan waktu dalam proses pembelajaran.

Tabel 5. Refleksi Siklus II

\begin{tabular}{|c|c|c|}
\hline $\mathrm{NO}$ & Masalah & Pemecahan Masalah \\
\hline 1 & $\begin{array}{l}\text { Pembelajaran terlambat dilakukan } \\
\text { dikarenakan. Perpindahan jam pelajaran } \\
\text { yang awal nya siswa belajar di kelas } \\
\text { kemudian siswa harus berpindah ke } \\
\text { labolatorium komputer dan hal itu cukup } \\
\text { menghamburkan waktu. }\end{array}$ & $\begin{array}{l}\text { Alangkah lebih baik jika ingin melakukan pembelajaran } \\
\text { di labolatorium komputer, guru memilih jam pelajaran } \\
\text { pada jam pertama dan di sela-sela setelah istirahat agar } \\
\text { lebih mudah untuk mengkondisikan waktu. }\end{array}$ \\
\hline 2 & $\begin{array}{l}\text { Pada saat akan memulai pembelajaran di } \\
\text { labolatorium komputer masih terdapat } \\
\text { beberapa komputer yang tidak bisa } \\
\text { digunakan }\end{array}$ & $\begin{array}{l}\text { Jauh sebelum dilaksanakannya pembelajaran guru harus } \\
\text { mengecek kinerja komputer yang tersedia. Jika ada } \\
\text { beberapa komputer yang rusak maka guru harus dapat } \\
\text { mengkondisikan kelas agar semua siswa dapat } \\
\text { menjalankan komputer secara bergantian dan teratur. } \\
\text { Dan menghubungi petugas labolatorium komputer agar } \\
\text { komputer segera diperbaiki. }\end{array}$ \\
\hline 3 & $\begin{array}{l}\text { Pembelajaran berlangsung terburu buru } \\
\text { menjelang akhir pembelajaran karena } \\
\text { keterbatasan waktu sehingga pada kegiatan } \\
\text { akhir pembelajaran berlangsung kurang } \\
\text { efektif. }\end{array}$ & $\begin{array}{l}\text { Guru harus dapat mengkondisikan waktu dengan baik } \\
\text { walaupun terjadi keterlambatan di awal pelajaran karena } \\
\text { masalah teknis yang tidak di sengaja. }\end{array}$ \\
\hline
\end{tabular}

Pada siklus II ketuntasan belajar siswa mencapai 85,7\% sebanyak 24 orang. Berarti masih ada 4 siswa yang tidak tuntas karena siswa yang hadir pada siklus I terdapat 28 siswa. Sedangkan kemampuan komunikasi matematis siswa pada tes siklus I dapat dilihat pada Tabel 6. Hasil tes kemampuan komunikasi matematis pada siklkus II memperlihatkan masih ada siswa yang mendapatkan nilai kurang dari batas ketuntasan sebanyak 1 siswa.

Tabel 6. Kemampuan Komunikasi Matematika Siswa Pada Tes Siklus II

\begin{tabular}{ccc}
\hline $\begin{array}{c}\text { Persentase Kemampuan Komunikasi } \\
\text { Matematika }\end{array}$ & Kriteria & $\begin{array}{c}\text { Jumlah } \\
\text { Siswa }\end{array}$ \\
\hline $\mathbf{9 0} \leq \mathbf{A} \leq \mathbf{1 0 0}$ & Sangat Baik & 4 \\
$\mathbf{7 5} \leq \mathbf{B}<\mathbf{9 0}$ & Baik & 15 \\
$\mathbf{5 5} \leq \mathbf{C}<\mathbf{7 5}$ & Cukup & 8 \\
$\mathbf{4 0} \leq \mathbf{D}<\mathbf{5 5}$ & Kurang & 1 \\
$\mathbf{0} \leq \mathbf{E}<\mathbf{4 0}$ & Jelek & 0 \\
\hline Total & 28 \\
\hline
\end{tabular}

\section{Siklus III (Tiga)}

Gambaran Aktivitas Siswa dalam proses pembelajaran matematika dengan menggunakan Adobe Flash pada siklus ketiga dapat dilihat pada Tabel 7. Pada siklus III yang belum terlaksana 
$100 \%$ adalah tahap II, yatiu pelaksanaan pembelajaran dengan Adobe Flash karena ada computer yang tidak medukun atau rusak.

Tabel 7. Gambaran Aktivitas Siswa pada Siklus III

\begin{tabular}{cccc}
\hline $\begin{array}{c}\text { Tahap } \\
\text { pembelajaran }\end{array}$ & Keterlaksanaan & Interpretasi & Komentar Observer \\
\hline Tahap I & $100 \%$ & Sangat baik & Kelas sudah mualai terkondisi \\
Tahap II & $83 \%$ & Sangat baik & $\begin{array}{c}\text { Pembelajaran sudah berjalan efektif } \\
\text { untuk kedepan nya agar bisa di } \\
\text { pertahankan dan di tingkatkan } \\
\text { Tes berlangsung kondusif dan } \\
\text { terkendali }\end{array}$ \\
\hline
\end{tabular}

Rata-rata aktivitas guru selama pembelajaran siklus III mencapai 100\% dengan kriteria sangat baik. Hasil refleksi siklus III dapat dilihat pada Tabel 8. Hasil dari observasi, pelaksanaan pembelajaran Matematika dengan Adobe Flash sudah terlaksana dengan baik. Namun guru harus mengecek komputer yang akan digunakan saat pembelajaran.

Tabel 8. Refleksi Siklus III

\begin{tabular}{|c|c|c|}
\hline NO & Masalah & Pemecahan Masalah \\
\hline 1 & $\begin{array}{l}\text { Pada saat akan memulai } \\
\text { pembelajaran di labolatorium } \\
\text { komputer masih terdapat beberapa } \\
\text { komputer yang tidak bisa digunakan }\end{array}$ & $\begin{array}{l}\text { Jauh sebelum dilaksanakannya pembelajaran guru } \\
\text { harus mengecek kinerja komputer yang tersedia. } \\
\text { Jika ada beberapa komputer yang rusak maka guru } \\
\text { harus dapat mengkondisikan kelas agar semua } \\
\text { siswa dapat menjalankan komputer secara } \\
\text { bergantian dan teratur. }\end{array}$ \\
\hline 2 & $\begin{array}{l}\text { Pada saat pembelajaran berlangsung } \\
\text { ada beberapa siswa yang menjalankan } \\
\text { komputer tidak sesuai dengan arahan } \\
\text { guru }\end{array}$ & $\begin{array}{l}\text { Guru harus dapat memantau seluruh siswa agar } \\
\text { tidak ada siswa yang main-main ketika belajar }\end{array}$ \\
\hline
\end{tabular}

Pada siklus III ketuntasan belajar siswa mencapai 94,28\% sebanyak 31 orang. Berarti masih ada 2 siswa yang tidak tuntas dari 35 siswa. Sedangkan kemampuan komunikasi matematis siswa pada tes siklus I dapat dilihat pada Tabel 9. Hasil tes pada siklus II memperlihatkan tidak ada siswa yang mendapatkan nilai kurang dari batas ketuntasan.

Tabel 9. Kemampuan Komunikasi Matematika Siswa Pada Tes Siklus III

\begin{tabular}{ccc}
\hline $\begin{array}{c}\text { Persentase Kemampuan Komunikasi } \\
\text { Matematika }\end{array}$ & Kriteria & $\begin{array}{c}\text { Jumlah } \\
\text { Siswa }\end{array}$ \\
\hline $\mathbf{9 0} \leq \mathbf{A} \leq \mathbf{1 0 0}$ & Sangat Baik & 10 \\
$\mathbf{7 5} \leq \mathbf{B}<\mathbf{9 0}$ & Baik & 20 \\
$\mathbf{5 5} \leq \mathbf{C}<\mathbf{7 5}$ & Cukup & 3 \\
$\mathbf{4 0} \leq \mathbf{D}<\mathbf{5 5}$ & Kurang & 0 \\
$\mathbf{0} \leq \mathbf{E}<\mathbf{4 0}$ & Jelek & 0 \\
\hline Total & 33 \\
\hline
\end{tabular}

Secara keseluruhan, aktivitas siswa pada setiap siklus dapat dilihat pada Tabel 10. Tabel 10 memperlihat rata-rata prosentase kenaikan yang terjadi pada setiap siklusnya. Pada tahap I dan III, setiap siklus mengalami kenaikan prosentase. Sedangkan pada tahap II terjadi penurunan prosentase dari siklus II ke III. Hal ini terjadi karena ada komputer yang tidak mendukung pembelajaran matematika denagn Adobe Flash. 
Tabel 10. Rata-rata Aktivitas Siswa Tiap Tahap pada Setiap Siklus

\begin{tabular}{lccccc}
\hline No & Siklus Ke- & \multicolumn{3}{c}{ Tahap } & Rata-rata \\
& & I & II & III & \\
\hline $\mathbf{1}$ & I & 75 & 83 & 75 & 78,57 \\
$\mathbf{2}$ & II & 100 & 100 & 75 & 92,85 \\
$\mathbf{3}$ & III & 100 & 83 & 100 & 92,85 \\
\hline
\end{tabular}

Pada tes akhir yang dilakukan, siswa yang mengikuti tes akhir ada 32 siswa. Hasil ketuntasan tes akhir setelah semua siklus dilakukan diperoleh sebanyak 28 siswa yang tuntas dan 4 siswa yang tidak tuntas dalam pembelajaran dengan menggunakan Adobe Flash atau sebesar 87,5\% siswa tuntas. Pada Tabel 11, tergambar kemampuan komunikasi matematis siswa pada tes akhir dan semua siswa mendapatkan kriteria cukup yang berarti semua siswa memiliki kemampuan komunikasi matematis.

Tabel 11. Kemampuan Komunikasi Matematik Siswa pada Tes Akhir

\begin{tabular}{ccc}
\hline $\begin{array}{c}\text { Persentase Kemampuan } \\
\text { Komunikasi Matematika }\end{array}$ & Kriteria & $\begin{array}{c}\text { Jumlah } \\
\text { Siswa }\end{array}$ \\
\hline $\mathbf{9 0} \leq \mathbf{A} \leq \mathbf{1 0 0}$ & Sangat Baik & 3 \\
$\mathbf{7 5} \leq \mathbf{B}<\mathbf{9 0}$ & Baik & 20 \\
$\mathbf{5 5} \leq \mathbf{C}<\mathbf{7 5}$ & Cukup & 9 \\
$\mathbf{4 0} \leq \mathbf{D}<\mathbf{5 5}$ & Kurang & 0 \\
$\mathbf{0} \leq \mathbf{E}<\mathbf{4 0}$ & Jelek & 0 \\
\hline Total & $\mathbf{3 2}$ \\
\hline
\end{tabular}

Untuk ketuntasan materi dapat dilihat pada Tabel 12. Berdasarkan Tabel 12, siswa mengalami kenaikan ketuntasan setiap siklusnya dalam pembelajaran matematika pada materi segiempat. Hal ini menandakan bahwa pembelajaran dengan menggunakan Adobe Flash efektif pada pembelajaran materi segiempat.

Tabel 12. Tingkat Ketuntasan Belajar Siswa pada Materi Segiempat

\begin{tabular}{ccc}
\hline Tes Evaluasi & Ketuntasan Belajar (\%) & Kriteria Ketuntasan \\
\hline Siklus I & 74,07 & Cukup \\
Siklus II & 85,70 & Baik \\
Siklus III & 94,28 & Sangat Baik \\
\hline
\end{tabular}

Selain ketuntasan pada materi pembelajaran segiempat, sikap siswa terhadap pembelajaran dengan menggunakan Adobe Flash juga mendapatkan respon yang positif. Hal ini dapat dilihat pada Tabel 13. 
Tabel 13. Persentase Sikap Siswa terhadap Pembelajaran Menggunakan Media Pembelajaran Adobe Flash

\begin{tabular}{|c|c|c|c|}
\hline No soal & Jenis & $\begin{array}{l}\text { Prosentase } \\
\text { Sikap Positif }\end{array}$ & $\begin{array}{l}\text { Prosentase } \\
\text { Sikap Negatif }\end{array}$ \\
\hline & & $\%$ & $\%$ \\
\hline $\begin{array}{l}\text { Media pembelajaraan yang dibuat menggunakan Adobe } \\
\text { Flash sangat menyenangkan }\end{array}$ & Positif & 93,75 & 6,25 \\
\hline $\begin{array}{l}\text { Media pembelajaraan yang dibuat menggunakan Adobe } \\
\text { Flash membuat saya malas belajar matematik }\end{array}$ & Negatif & 96,88 & 3,13 \\
\hline $\begin{array}{l}\text { Penggunaan media pembelajaran Adobe Flash membuat } \\
\text { suasana pembelajaran di kelas terasa lebih nyaman }\end{array}$ & Positif & 90,63 & 9,38 \\
\hline $\begin{array}{l}\text { Saya merasa pusing setelah pembelajaran yang } \\
\text { menggunakan media Adobe Flash }\end{array}$ & Negatif & 84,38 & 15,63 \\
\hline $\begin{array}{l}\text { Gambar-gambar yang ada dalam media pembelajaran } \\
\text { Adobe Flash sangat menarik sehingga membuat saya } \\
\text { fokus belajar matematik }\end{array}$ & Positif & 96,88 & 3,13 \\
\hline $\begin{array}{l}\text { Saya menjadi takut belajar matematika setelah } \\
\text { penngunaan media pembelajaran Adobe Flash } \\
\text { Animasi yang ada dalam media pembelajaran Adobe }\end{array}$ & Negatif & 93,75 & 6,25 \\
\hline $\begin{array}{l}\text { Flash membuat saya menjadi lebih paham mengenai } \\
\text { materi yang sedang dipelajari }\end{array}$ & Negatif & 96,88 & 3,13 \\
\hline $\begin{array}{l}\text { Saya tidak ingin pembelajaran matematika menggunakan } \\
\text { media pembelajaran Adobe Flash. }\end{array}$ & Positif & 93,75 & 6,25 \\
\hline $\begin{array}{l}\text { Soal - soal segiempat mengenai kemampuan komunikasi } \\
\text { matematika membuat saya tertantang untuk bisa } \\
\text { mengerjakan soal aplikasinya. }\end{array}$ & Negatif & 90,63 & 9,38 \\
\hline $\begin{array}{l}\text { Saya tidak suka soal komunikasi matematika yang } \\
\text { behubungan dengan kehidupan sehari-hari. }\end{array}$ & Positif & 96,88 & 3,13 \\
\hline $\begin{array}{l}\text { Saya senang mengerjakan soal-soal kemampuan } \\
\text { komunikasi matematika pada pokok bahasan segiempat. }\end{array}$ & Positif & 96,88 & 3,13 \\
\hline
\end{tabular}

Berdasarkan hasil penelitian yang telah dipaparkan maka kemampuan komunikasi matematis siswa mengalami peningkatan di setiap siklusnya setelah menggunakan pembelajaran dengan media Adobe Flash. Hal ini menandakan bahwa pembelajaran Matematika dengan media Adobe Flash dapat membuat siswa lebih aktif sehingga kemampuan komunikasi matematisnya meningkat (Bernard, 2015). Hal yang sama diungkapkan bahwa media Adobe Flash dapat meningkatkan keefektifan dalam pembelajaran Matematika (Novyarti, Marzal, \& Rohati).

\section{Kesimpulan}

Pembelajaran dengan menggunakan media Adobe Flash dapat meningkatkan kemampuan komunikasi matematis siswa dengan kategori baik dilihat dari peningkatan yang terjadi dari siklus I sebanyak 78,57, siklus II dan III sebanyak 92,85. Diperkuat juga dengan tingkat ketuntasan belajar siswa pada materi segiempat yakni pada siklus I cukup tuntas dengan 74,07\%, meningkat baik di siklus II menjadi $85,70 \%$, dan menjadi sangat baik dengan nilai ketuntasan $94,28 \%$ pada siklus III. Sehingga pembelajaran dengan media Adobe Flash dapat dijadikan sebagai salah satu alternatif dalam pembelajaran matematika pada materi segiempat.

\section{REFFERENCES}

Aesih, C. (2014). MENINGKATKAN KEMAMPUAN KOMUNIKASI DAN PEMAHAMAN MATEMATIK SERTA MINAT MEMBACA SISWA SMP MELALUI STRATEGI SQ3R. In Prosiding Seminar Nasional Matematika STKIP Siliwangi. 
Aji, S. D., Hudha, M. N., \& Gufran, G. (2018). Computer Animation with Adobe Flash Professional Cs6 in Newton's Computer Animation with Adobe Flash Professional Cs6 in Newton's Law. In The 2nd Annual Appied Science and Engineering Conference (AASEC 2017) (pp. 1-4). https://doi.org/10.1088/1757-899X/288/1/012131

Baroody. (1993). Problem Solving, Reasoning, and Communication, K-8, Helping Children Think Mathematically. New York: Macmillan Publishing Company.

Kirana, Y. C. (2014). PERANAN PENDEKATAN KONTEKSTUAL TERHADAP PENINGKATAN KEMAMPUAN KOMUNIKASI MATEMATIK. In Prosiding Seminar Nasional Matematika STKIP Siliwangi.

Minarti, E. D. (2014). Penerapan Media Komputer dengan Menggunakan Macromedia Flash Terhadap Hasil Belajar Matematika Siswa SMP. In Seminar Nasional Matematika STKIP Siliwangi. Cimahi.

Novitasari, D. (2016). Pengaruh Penggunaan Multimedia Interaktif Terhadapa Kemampuan Pemahaman Konsep Matematis Siswa. Fibonacci Jurnal Pendidikan Matematika Dan Matematika, Volume 2 N, 8-18.

Nurismayanti. (2014). Mengembangkan Kemampuan Komunikasi dan Pemecahan Masalah Matematis serta Kepercayaan Diri Siswa SMA dalam Pembelajaran Matematika. In Prosiding Seminar Nasional Matematika SKTIP Siliwangi.

Paridjo; Waluya, S. B. (2017). Analysis Mathematical Communication Skills Students In The Matter Algebra Based Nctm, 13(I), 60-66. https://doi.org/10.9790/5728-1301056066

Supriyadi. (2016). Adobe Flash Untuk Mendukung Pembelajaran. Jurnal Komunikasi, VII(September), 38-42.

Sutopo, A. (2003). Multimedia Interaktif dengan Flash. Yogyakarta: Graha Ilmu.

Utami, C., Dwijayanto, \& Djuniadi. (2015). PEMBELAJARAN MODEL GENERATIF DENGAN STRATEGI GROUP INVESTIGATION UNTUK MENINGKATKAN KEMAMPUAN KOMUNIKASI MATEMATIS SISWA Abstrak. Unnes Journal of Mathematics Education Research (UJMER), 4(1), 26-33.

Bernard, M. (2015). Meningkatkan Kemampuan Komunikasi dan Penalaran serta Disposisi Matematika Siswa SMK dengan Pendekatan Kontekstual Melalui Game Adobe Flash CS 4.0. Infinity Jurnal Ilmiah Program Studi Pendidikan Matematika STKIP Siliwangi Volume 2 No 2, 197-222.

Novyarti, E., Marzal, J., Rohati. (2014). Pengembangan Media Pembelajaran Menggunakan Adobe Flash dan Autoplay Media Studio dalam Pembelajaran Berbasis Inquiry pada Materi Garis dan Sudut Kelas VII SMP. Edumatica Vol 4 NO 2 (Oktober), 78-84. 